\title{
TASAS POR LICENCIAS DE OBRAS FUERA DE POBLADO Y NO CONTIGUAS A VIAS MUNICIPALES
}

351.778 .511

por

Antonio Martínez Blanco

Secretario de Administración local

SUMARIO: I. INTRODUCCION.-II. DOCTRINA JURISPRUDENCIAL SOBRE EL ARTICULO 440, EN SUS PARRAFOS 7 Y 26, DE LA LEY DE REGIMEN LOCAL.-III. DOCTRINA DE LA DIRECCION GENERAL DEL TESORO Y PRESUPUESTOS. - IV. CONSECUENCIAS.

\section{INTRODUCCION}

Una resolución de la Dirección General del Tesoro y Presupuestos, de 27 de mayo de 1972 (Boletin de los Cuerpos Nacionales, junio de 1972, pág. 581), ha venido a poner de actualidad la debatida cuestion de si es procedente el cobro de tasa municipal por licencia de obra en construcciones fuera de poblado y no contiguas a vías municipales, sentando, por otra parte, unos criterios que parecen diferir de los mantenidos hasta ahora por la jurisprudencia de nuestro más Alto Tribunal.

Ello comporta consecuencias prácticas de confusión para los profesionales de la Administración local en un tema de indudable trascendencia económica para las Corporaciones y en una época de expansión y crecimiento de nuestra industria, que busca, fuera de los poblados y normalmente cerca de grandes vías de comuni- 
cación, la ubicación óptima para evitar la contaminación del ambiente de las ciudades y las mejores posibilidades de comunicación.

La práctica tradicional de nuestros Ayuntamientos ha sido, por otra parte sin una mayor discriminación, liquidar y percibir tasas por toda clase de obras ralizadas dentro del término municipal, sin que los afectados protestaran por ello, al amparo de ordenanzas fiscales aprobadas conforme al artículo 440 , número 7 , de la Ley de Régimen local; normalmente se ha tratado de construcciones rústicas, contiguas a vías municipales $o$ no, incluso sitas en el interior de las explotaciones agrícolas sin una colindancia a vía alguna oficial.

$\mathrm{Ha}$ sido al ventilarse cantidades importantes, liquidadas por obras fuera de poblado y no contiguas a vías municipales, normalmente llevadas a cabo por empresas de envergadura, cuando ha comenzado a plantearse en muchos Ayuntamientos la cuestión, que en ocasiones ha llegado a los Tribunales Territoriales de lo Contencioso y al mismo Tribunal Supremo.

Planteada así la cuestión, cabe preguntarse: ¿Cuál es el criterio de nuestro Tribunal Supremo sobre la cuestión? ¿Qué dice y en qué razón se apoya la citada jurisprudencia administrativa? ¿Qué deben hacer los Ayuntamientos?

\section{DOCTRINA JURISPRUDENCIAL SOBRE EL ARTICULO 440, EN SUS PARRAFOS 7 Y 26, DE LA LEY DE REGIMEN LOCAL}

El artículo 440 de la Ley de Régimen local establece: «Que se entenderán comprendidos en el número 1 del artículo 435 los conceptos siguientes:

7. Licencias para construcciones en terrenos sitos en poblado o contiguos a vías municipales fuera de poblado.

26. Cualquiera otros servicios de naturaleza análoga».

En concordancia con este artículo, el 435 de la Ley de Régimen local establece:

«1. Los Ayuntamientos podrán establecer derechos y tasas por prestación de servicios públicos municipales que beneficien especialmente a personas determinadas o se provoquen también especialmente por ellas». 
En concordancia con el número 26 citado, el Reglamento de Haciendas locales se refiere a los servicios públicos municipales de depósito de muebles, limpieza de chimeneas, uso de lavaderos, prestación voluntaria de útiles de pesar o medir, riego de plaza de toros y actuaciones que se soliciten de la banda de música.

La doctrina del Tribunal Supremo se halla contenida, entre otras, en las sentencias de 31 de octubre de 1961 (R. 3.262), de 2 de diciembre de 1966, de 5 de octubre de 1967 (R. 3.402), y de 24 de junio de 1968 (R. 3.499).

Se confirma en sentencias de Tribunales Territoriales: de 11 de mayo de 1964, Audiencia Territorial de Cáceres; de 15 de marzo de 1965, Audiencia Territorial de Cáceres, y de 18 de febrero de 1971, Audiencia Territorial de Albacete.

a) Concepto de poblado y de vías municipales.

Presupuesto previo para la recta interpretación del artículo 440, apartados 7 y 26, de la Ley de Régimen local, es la definición de los conceptos de vías municipales o de poblados sobre los que se fundamenta la posibilidad de imposición de tasas por licencias de obras.

Como sustantivo, según el Diccionario de la Lengua, poblado significa "población, ciudad, villa o lugar", tesis que recoge la sentencia del Tribunal Supremo de 30 de octubre de 1956 (R. 3.556). Haciendo, pues, una interpretación gramatical del número 7 del artículo 440 de la Ley de Régimen local vemos que el vocablo está utilizado como sustantivo (Considerando $4 .^{\circ}$ de la sentencia de la Audiencia Territorial de Sevilla, confirmada por el Tribunal Supremo en la suya de 5 de octubre de 1967 (R. 3.402).

Según el número 24 del artículo 444 de la Ley de Régimen local se entienden por vías municipales todas aquellas cuyo entretenimiento y conservación esté en todo o en parte a cargo del Ayuntamiento (sentencia del Tribunal Supremo de 10 de octubre de 1961, citada por la del Tribunal Supremo de 5 de octubre de 1967, R. 3.402).

El caso planteado en la sentencia de 5 de octubre de 1967 se refiere a obras de construcción de una fábrica y almacenes para algodón de una Cooperativa al lado de la carretera 438 , Córdoba a Sevilla, la cual tiene carácter exclusivamente estatal y su conservación se sufraga con fondos del Estado; los terrenos distan 50 metros del lado de la misma; los caminos existentes son simples caminos rurales de acceso a las diversas fincas rústicas allí existentes; los 
dos núcleos de población más próximos son una barriada y un poblado sitos a dos kilómetros y medio y a un kilómetro novecientos metros de los terrenos, respectivamente, y más alejados del casco urbano de Córdoba; no existe ninguna edificación contigua, y las más próximas están a un centenar de metros y corresponden a explotaciones agrícolas, ni tampoco casas sin solución de continuidad; no se opone a lo dicho que la zona tenga alta densidad de población, ni que exista una línea de autobuses con diversas paradas intermedias, ni diversas acometidas de energía eléctrica, pues todo ello es propio de una zona de regadío; no se ha probado que el servicio de adquisición de los terrenos sea superior al de su primitivo destino rústico, pero de los autos no se deduce que tenga los requisitos que exige la Ley del Suelo para poderlos conceptuar como solares. De todo ello se deduce que los terrenos no están incluidos en poblado ni contiguos a vía municipal.

La sentencia de la Audiencia Territorial de Albacete de 18 de febrero de 1971 se refiere a naves construidas fuera de poblado, a una distancia de tres kilómetros setecientos metros del más próximo y a la misma distancia de un camino ubicado en terreno rústico, rodeado de lomas incultas que sólo producen pastos.

Los ejemplos citados bastan para dar idea de las dificultades que pueden presentarse a la hora de calificar el hecho y presupuesto básico de la ubicación de los terrenos. Pero es cuestión que habrá que dilucidar en cada caso $\mathrm{y}$, por otra parte, escapa al objeto de nuestra preocupación en estos momentos.

b) Al amparo del número 7 del artículo 440 de la Ley de Régimen local no pueden establecerse ordenanzas ni girar tasas por licencias de obras fuera de poblado o contiguas a vías municipales fuera de poblado.

Esta conclusión es clara, y no admite contradicción, en nuestra jurisprudencia; una ordenanza fiscal aprobada al amparo del número 7 del artículo 440 de la Ley de Régimen local no cubre el supuesto de obra fuera de poblado y no contiguo a vía municipal. En este sentido, la práctica municipal ha sido viciosa, hay que suponer que por inadvertencia, y debe ser rectificada en lo sucesivo en evitación de reclamaciones o responsabilidades.

La doctrina del Tribunal Supremo arranca de la naturaleza de la tasa y del principio de legalidad impositiva: su texto básico lo constituye la sentencia del Tribunal Supremo de 24 de junio de 1968 (R. 3.499), que explicitamos: 
1. La tasa es forma de tributación pecuniaria debida a la Administración por la realización de un servicio, que afecta de modo particular al obligado a su pago (sentencia del Tribunal Supremo de 26 de octubre de 1965, R. 4.615).

2. La tasa es únicamente exigible "cuando una norma con valor de ley impone la tasa y en la medida que lo establece», por lo que no basta con que la Administración realice una actividad y que ésta afecte de modo particular a una persona, sino que además es necesario que una ley, y en la medida que la misma disponga, autorice la percepción.

3. Tratándose de tasas municipales se requiere también una ordenanza complementaria que la reglamente y desarrolle. Se citan a estos efectos los artículos 9. del Fuero de los Españoles y 27 de la Ley de Régimen local.

4. Se elimina de este modo cualquier equívoco sobre la misión del intérprete, o aplicador de la misma, ya agente de la Administración o componente de un Tribunal de Justicia, pues, al encontrarnos ante una materia "reservada a la ley», no es posible pensar en discrecionalidad, ni en el sentido de lo justo, ni aun siquiera en los principios generales del Derecho; la ley es la fuente soberana que por sí sola, sin adherencias extrañas, ha de decidir el problema.

Parece, no obstante, que el Tribunal Supremo ha ido en este caso un poco lejos en ciertos aspectos o matices.

5. En el caso del artículo 440, número 7 , de la Ley de Régimen local, la Ley ha sido bien explícita, pues no se ha limitado a establecer una tasa en supuesto de peticiones de licencias de obras a los Municipios, sino que se ha concretado en qué casos la exacción será exigible, esto es, ha recortado de los supuestos imaginables un tipo de ellos y con él ha creado el tipo legal, que las obras se realicen en poblado o contiguas a vías municipales fuera de poblado, lo que equivale a dejar fuera de su ámbito a aquellas obras a realizar en lugares no comprendidos en el cliché legal.

6. No es de aplicación la norma analógica del artículo 440, número 26 , que sujeta también a imposición "cualesquiera otros servicios de naturaleza análoga», ya que ello supondría no la aplicación de una analogía, sino una interpretación extensiva del número 7 del mismo artículo. Esta es un medio interpretativo dirigido a corregir los términos excesivamente restrictivos de la Ley (minus 
dixit quam voluit), ampliando la letra de la misma hasta comprender todos los supuestos implícitamente queridos por el legislador. Es evidente que una interpretación de esta índole no cabe en materia fiscal, en que prevalece el principio de legalidad y tipificación, por estar perfectamente fijado el tipo impositivo en el número 7 del artículo de la Ley de Régimen local.

Bien entendido que lo que aquí se afirma por el Tribunal Supremo, cuya doctrina puede compartirse sin violencia, es que una ordenanza fiscal aprobada al amparo del número 7 del artículo 440 de la Ley de Régimen local no puede amparar el cobro de derechos por licencias de obras fuera de poblado y no contiguas a vías municipales; en este sentido dice que no es de aplicación la analogía regulada en el número 26 del mismo artículo, pues no se trataría de analogía, sino de interpretación extensiva.

Distinto es el problema de si al amparo de la analogía prevista en dicho precepto es posible crear una figura impositiva nueva por licencias fuera de poblado y no contiguas a vías municipales.

7. No es argumento suficiente en contra el hecho de que sea necesaria y se otorgue licencia municipal para obras fuera de poblado y no contiguas a vías municipales. Efectivamete, la Ley del Suelo en sus artículos 165 y 166, sobre la competencia municipal, hacen necesaria la licencia de obras en cuantas se realicen dentro del término municipal. Ello podría hacer suponer que se ha superado la ratio legis del legislador de 1955 (el de la Ley de Régimen local), puesto que no basta con que la Administración realice una actividad y que ésta afecte de modo particular a una persona, sino que, además, es necesario que una ley, y en la medida que la misma disponga, autorice la percepción (sentencia de 26 de octubre de 1965, R. 4.615). Esa ley falta en el presente caso.

Por otra parte, el Alto Tribunal quiere deshacer también el argumento de la falta de ratio legis al poner de manifiesto que la diferencia de fechas entre la Ley de Régimen local, que autoriza la tasa (1955), y la Ley del Suelo, que impone el servicio en toda la extensión del término municipal (1956), no supone nada, pues no han faltado ocasiones en las posteriores reformas de las Haciendas locales para haber podido corregir semejante discordancia y, no obstante, se ha mantenido el régimen anterior, el de la Ley de Régimen local de 1955.

Tampoco es totalmente convincente este argumento. Si el legislador no ha querido modificar el número 7 del artículo 440 habrá 
tenido sus razones políticas o de oportunidad. Pero no cabe duda que donde la razón es la misma, la misma debe ser la norma de derecho. De iure condendo no hay razón para que se paguen tasas en un caso y en otro no, siendo el servicio que se presta al particular el mismo, esto es, el otorgamiento de una licencia de obras, sea en poblado o fuera del mismo, contigua a vía municipal o no; pues extendiéndose la actividad urbanística a todo el término municipal, con posibilidad incluso de Planes territoriales para todo el término, el servicio de vigilancia y comprobación de las condiciones de edificación, sanidad y seguridad, etc., incluso ornato (tratándose de edificios visibles desde las vías públicas o incluso en perspectivas panorámicas), es totalmente idéntico.

La competencia de la Corporación se extiende a la protección y defensa del paisaje en su artículo 101, junto con la materia urbanística y policía de la construcción.

Los artículos 138 de la Ley de Régimen local y 21 del Reglamento de Servicios regulan la concesión de licencias de obras y construcciones en terrenos que no tienen la condición de solares o de nuevas urbanizaciones, que son normalmente los situados fuera de poblado (resolución de la Dirección General del Tesoro y Presupuestos).

8. Una ordenanza fiscal, creada al amparo del número 7 del artículo 440, para que abarcara también las obras fuera de poblado o no contiguas a vías municipales, es decir, que extienda a todo el término municipal las facultades que el artículo 440, número 7, sólo autoriza para obras en poblado o contiguas a vías municipales fuera de poblado, carece de viabilidad o aplicabilidad, habiéndose de estar en tales supuestos a lo que expresamente se dispusiera en las leyes a las que las ordenanzas fiscales deben su razón de existencia, pues las Haciendas locales ni pueden crear tasas ni establecerlas saliéndose de los límites marcados en las normas de superior jerarquía. Una ordenanza de tal índole no autoriza la imposición por aplicación del artículo 440, número 26 , pues ello requerirá que previamente el Ayuntamiento acordara la imposición y aprobara la correspondiente ordenanza para percibir derechos y tasas del número 26 citado.

9. Ello nos lleva como de la mano al problema, más complicado, de si puede el Ayuntamiento acordar la imposición de una nueva tasa por licencias de obras fuera de poblado y no contiguas a 
vías municipales, al amparo del número 26 del tan repetido artículo de la Ley de Régimen local, figura que tendría una configuración de similares características a la del número 7 .

En este sentido, la jurisprudencia parece que no es partidaria de tal nueva figura impositiva al amparo del número 26. Realmente el caso no se ha presentado de modo directo hasta la fecha, que sepamos, pero tangencialmente, y a propósito de un caso de aplicación de la ordenanza creada al amparo del número 7, a todo el término municipal invocando el número 26 (sentencia de 24 de junio de 1968) parece excluir tal posibilidad.

En la analogía se suele ver, dice, un procedimiento intermedio entre la pura interpretación y la producción de Derecho para llenar las lagunas de la Ley; en realidad, la analogía, sigue diciendo, se apoya sobre la Ley, pero presume que el caso de que se trata no está regulado por ésta (Considerando 11 de la sentencia apelada que recoge la sentencia del Tribuna Supremo citada), y saca la conclusión de que, como ha proclamado la jurisprudencia (sentencia del Tribunal Supremo, Sala 1. a, R. 997), "cuando hay una ley aplicable a un caso no es lícito acudir a la analogía, ya que en este supuesto, y en virtud del argumento a contrario sensu, inclusio unius, exclusio alterius»; y así, existiendo la posibilidad de gravar con tasa "cualesquiera otros servicios de naturaleza análoga» a los 25 enumerados en el artículo 440 de la Ley de Régimen local, tal permisión desaparece cuando, en casos como el de autos, el servicio viene configurado en uno de esos números, a efectos de gravamen, fiscal, con el propósito explícito en el texto de que este gravamen sólo en las circunstancias descritas en el mismo se produzca (cfr. Considerando 12 de la sentencia apelada, que es recogida por la sentencia del Tribunal Supremo).

Pero creemos que la jurisprudencia en este caso incurre en una lamentable confusión, pues al establecerse una figura impositiva nueva al amparo del apartado 26 del artículo 440 de la Ley de Régimen local, no se está haciendo aplicación de la analogía en la creación o interpretación del Derecho. Se está simplemente aplicando una Ley clara, la del precepto 26 de dicho artículo. Lo que sucede es que el contenido material de dicho precepto, a saber, la figura impositiva nueva, habiendo enumerado las más frecuentes, o convenientes, puede ser de análogas características a las enumeradas. Por ello no es de aplicación el principio de que cuando haya ley aplicable a un caso no es lícito acudir a la analogía, pues 
en el presente caso no se acude a la analogía precisamente porque existe una Ley, la del número 26.

Sucede, además, que enumerándose los más diversos servicios públicos municipales, que fundamentan el derecho a poder establecer tasas (art. 435 de la Ley de Régimen local), el grado de analogía de las posibles nuevas figuras al amparo del número 26 puede ser muy diverso, según el número de elementos jurídicos en que coincidan con las ya reguladas expresamente. En el caso de licencias de obras fuera de poblado o no contiguas a vías municipales, el grado de analogía es caso absoluto, pues siendo esencialmente idéntica la actividad de la Administración ejercitada, la variación, que justifica y fundamenta la nueva imposición, se refiere tan sólo al lugar, a la parte de territorio municipal en que se ejerce la misma.

¿Puede concluirse entonces que el hecho de haberse previsto en el número 7 las obras dentro de poblado o contiguas a vías municipales excluya la posibilidad de crear la figura «análoga» de obras fuera de poblado y no contiguas a vías municipales? En modo alguno. El hecho de que en este supuesto la analogía con una figura prevista en la ley sea mayor, no excluye la creación de figura impositiva distinta formalmente, idéntica en cuanto a la sustancia del servicio que se presta, aunque referido a lugar distinto.

\section{DOCTRINA DE LA DIRECCION GENERAL DEL TESORO Y PRESUPUESTOS}

La oportunidad de la resolución de la Dirección General del Tesoro y Presupuestos de fecha 29 de mayo de 1972 (Boletín de los Cuerpos Nacionales de Administración Local) no ha podido ser mayor. Su interés es evidente desde el punto de vista doctrinal y no menos desde el punto de vista práctico en orden al reforzamiento de los ingresos municipales por el concepto de licencias de obras.

El supuesto de hecho fue el siguiente. El Ayuntamiento de Alginet acordó la imposición de «tasa por la intervención municipal en el otorgamiento de licencias para las instalaciones, construcciones y obras en terrenos sitos en el extrarradio no contiguios a vías municipales del término muncipal», que, previos a los trámites re- 
glamentarios, se elevó a la Delegación de Hacienda de Valencia, la que sancionó desfavorablemente la referida imposición en virtud de los criterios sentados por la jurisprudencia del Tribunal Supremo en sus sentencias de 5 de octubre de 1967 y 24 de junio de 1968 (estudiadas), cuyos argumentos son fundamentalmente que no siempre que sea necesaria la licencia municipal para efectuar obras tiene el Municipio facultad para percibir tasas por la expedición de dichas licencias, y que la configuración del servicio municipal de otorgamiento de licencia en el número 7 del artículo 440 de la Ley de Régimen local impide la aplicación analógica del número 26 del mismo artículo.

Al recurrir el Ayuntamiento ante la Dirección General alega aquél que no existe interpretación extensiva del número 7 , sino la creación de figura fiscal distinta con análogas características económicas en cuanto al servicio, acogiéndose al número 26 del artículo 440, cuya exigibilidad se basa en la prestación de un servicio que cumple las condiciones del artículo 435,1 , de la Ley de Régimen local.

La Dirección General del Tesoro declara que es conforme a derecho la imposición de la tasa por intervención municipal en el otorgamiento de licencias para las instalaciones, construcciones y obras en terrenos sitios en el extrarradio no contiguos a vías municipales, por lo cual estima el recurso de alzada interpuesto por el Ayuntamiento de Alginet, ordenando se devuelva el expediente de imposición al momento en que fue recibido por la Delegación de Hacienda a fin de que ésta conozca en ejercicio de su competencia la ordenanza fiscal y tarifa.

La doctrina que sirve de base a esta conclusión puede resumirse en las siguientes directrices:

1. Las tasas constituyen una prestación pecuniaria debida a la Administración por la realización de un servicio que beneficie especialmente a personas determinadas.

2." Las tasas son susceptibles de imposición, aunque no se produzca petición de los interesados, siempre que sea por servicios de la competencia municipal y tengan carácter obligatorio en virtud de precepto general o por disposición de los Reglamentos $\mathrm{u}$ Ordenanzas de Policía local (así se deduce del artículo 10 del Reglamento de Haciendas locales).

3. Modalidad de estas Ordenanzas es la concesión de licencias de obras cuyo otorgamiento corresponde a las Corporaciones loca- 
les en virtud del artículo 101 de la Ley de Régimen local: competencia en materia urbanística, policía de construcción, protección y defensa del paisaje; esta competencia y obligación derivan del Reglamento de Actividades Molestas, Insalubres, Nocivas y Peligrosas.

4. ${ }^{a} \quad$ Los artículos 138 de la Ley de Régimen local y 21 del Reglamento de Servicios regulan más concretamente la concesión de licencias de obras y construcciones en terrenos que no tienen la condición de solares o de nuevas urbanizaciones, que son normalmente las situadas fuera de poblado.

5. $\quad$ Si bien el apartado 7 del artículo 440 de la Ley de Régimen local contempla únicamente el hecho imponible de licencias de construcciones sitas en poblado o contiguas a vías municipales, no debe olvidarse que el apartado 26 admite otras imposiciones de naturaleza análoga a las nominadas en los precedentes apartados, y que en el caso examinado se observan características técnicas similares en cuanto a la intervención de los servicios de peritos municipales para comprobar la adecuación de los proyectos y de las obras que se realicen a las normas de policía de edificación y una indudable similitud de hechos imponibles; todo ello fundamenta la legitimidad de una tasa que permita remunerar un servicio municipal compensando los costes a que dé lugar dicha actividad ejercida en virtud de preceptos legales.

6. Este criterio no violenta con una extensión indebida el hecho imponible del número $7 \mathrm{del}$ artículo 440 de la Ley de Régimen local, ni contradice la jurisprudencia recaída en torno a la interpretación de este último apartado, ya que la tasa cuya legalidad procede declarar tiene como propio fundamento el número $26 \mathrm{del}$ mismo artículo.

Comparando esta doctrina con la del Tribunal Supremo se advierte una contradicción esencial entre ambas, pues, según vimos, el Tribunal Supremo niega la posibilidad de crear una figura impositiva nueva análoga al amparo del artículo 440,26 , para percibir derechos o tasas por licencia de obras fuera de poblado sobre la base de que no es de aplicación la analogía, ya que hay Ley aplicable, la del número 7 del artículo 440 , y además por el principio inclusio unius, exclusio alterius. Postura ya criticada anteriormente en base a la confusión de la aplicación analógica del número 7, con la propia e independiente aplicación del número 26 , siquiera 
el supuesto de hecho de este último, el servicio que se presta, tenga analogía en grado máximo con el servicio previsto en el número 7.

En todo lo demás coinciden ambas interpretaciones: naturaleza de la tasa, posibilidad de su imposición obligatoria, aunque no medie petición de los interesados; limitación de la aplicación del número 7 al solo supuesto de obras en poblado o contiguas a vías municipales, no siendo posible su aplicación analógica a los supuestos de obras fuera de poblado y no contiguas a vías municipales, porque ésta sería interpretación extensiva y no aplicación de la analógica, etc. $\left(^{*}\right)$.

\section{CONSECUENCIAS}

El problema jurídico de fondo es, en definitiva, la posibilidad de cobrar licencia de obras por obras sitas fuera de poblado y no contiguas a vías municipales, siquiera sea precio para ello la imposición de una figura fiscal nueva con aprobación de su ordenanza y tarifa por los procedimientos reglamentarios.

Una cosa ha quedado clara, indubitada: la imposibilidad de percibir tasas por tal concepto al amparo de una ordenanza aprobada al amparo del número 7 del artículo 440 de la Ley de Régimen local, tal como se viene haciendo hasta la fecha por todos los Ayuntamientos.

Una consecuencia, no menos importante, viene a corregir el anterior efecto negativo, es decir, la posibilidad, al amparo de la resolución de la Dirección General del Tesoro y Presupuestos de 27 de mayo de 1972, de tramitar y aprobar la imposición de una figura fiscal nueva que grave el servicio de licencias municipales fuera de poblado no contiguo a vía municipal al amparo del número 26 del mismo artículo 440 de la Ley de Régimen local.

(*) Sin embargo, una resolución de la Delegación de Hacienda de Murcia de 4 de diciembre de 1972 ha aprobado una ordenanza reguladora de la nueva imposición de tasa por alicencias para construcciones y obras en terrenos fuera de poblados y no contiguos a vías municipales», del Ayuntamiento de Totana, al amparo del número $7 \mathrm{del}$ artículo 440 de la Ley de Régimen local.

En la Memoria de la Alcaldía se hacía alusión a la resolución de la Dirección General del Tesoro y Presupuestos de 27 de mayo de 1972, y el acuerdo municipal apoyó la nueva imposición en el número 26 del citado artículo 440 de la Ley de Régimen local. 
La base impositiva es evidente: se presta un servicio análogo al de licencias en el casco urbano o terrenos contiguos a vías municipales, con la intervención de funcionarios, peritos y autoridades municipales, en virtud de competencias propias municipales derivadas tanto del urbanismo como de la vigilancia de toda actividad que pueda resultar molesta, nociva o peligrosa. La lógica avala esta consecuencia, pues no hay razón para eximir de pago de tasas por licencia una actividad que se presta fuera de poblado, cuando se grava dentro del mismo, siendo idéntico el servicio prestado en base a un ensanchamiento del urbanismo, que es de hecho de ámbito territorial, abarcando todo el término del Municipio. El desfase entre las leyes fiscales y las urbanísticas no puede ser argumento para que de iure condendo desaparezca esta posibilidad de confusión y para que, al amparo del margen legal que autoriza el número 26 del citado artículo 440 de la Ley de Régimen local, pueda corregirse tan anómala situación, según una interpretación de tan autorizado organismo como la Dirección General del Tesoro y Presupuestos, que hemos visto descansa en sólido fundamento jurídico-científico.

Como, por otra parte, la expansión de nuestra economía y el proceso de desarrollo llevan a la creciente demanda de licencias de obras fuera de los poblados, lugares adecuados para las grandes industrias, que por imperativos reglamentarios deben estar en ciertos casos a dos kilómetros de la población (art. 4. ${ }^{\circ}$ del Reglamento de Actividades Molestas), no es difícil calcular que el montante de ingresos por este concepto suponga cantidades cuantiosas que son imprescindibles para nutrir las arcas municipales.

De todas formas queda la incógnita de lo que sucedería si una impugnación de ordenanza fiscal, aprobada al amparo del artículo 440,26 , de la Ley de Régimen local, llegara a nuestro Tribunal Supremo. La sentencia de 24 de junio de 1968, aunque incidentalmente, no se muestra partidaria de una solución favorable a los Ayuntamientos. La fuerza del antecedente de la resolución de una Dirección General, interpretación en cierto modo auténtica de la Ley de Régimen local, así como la lógica de los argumentos expuestos, pudieran inclinar a dicho Tribunal a una solución favorable.

Para evitar toda inseguridad jurídica, que es la misión propia del Derecho, sería conveniente que futuras reformas de la Ley de Régimen local revisaran el número 7 del artículo 440 para dar explícita cabida a las licencias de obras fuera de poblado y no contiguas a vías municipales. 
Entre tanto, los Ayuntamientos debieran acordar una tal imposición, formulando la ordenanza y tarifa correspondientes, que pueden no diferir sustancialmente de las referidas al casco urbano (salvo la materia de alineaciones o voladizos, superficie edificada, etc.), para poder, dentro de la legalidad, percibir unos ingresos lícitos y debidos al erario municipal. 